\title{
ENGLISH AS MEDIUM OF INSTRUCTION: LANGUAGE AND CONTENT COMBINATION IN DIGITIZED HighER ENGINEERING EDUCATION
}

\author{
Oleg Ipatov, Sofia Saramaha, Darina Barinova, \\ Anna Rubtsova \& Maria Odinokaya
}

Peter the Great St.Petersburg Polytechnic University
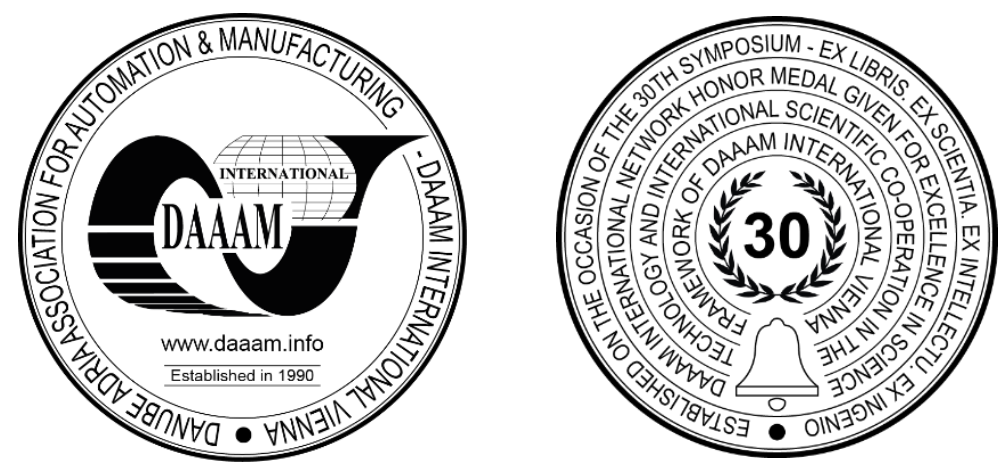

This Publication has to be referred as: Ipatov, O[leg]; Saramaha, S[ofia]; Barinova, D[arina]; Rubtsova, A[nna] \& Odinokaya, M[aria] (2021). English as Medium of Instruction: Language and Content Combination in Digitized Higher Engineering Education, Proceedings of the 32nd DAAAM International Symposium, pp.0168-0176, B. Katalinic (Ed.), Published by DAAAM International, ISBN 978-3-902734-33-4, ISSN 1726-9679, Vienna, Austria DOI: $10.2507 / 32$ nd.daaam.proceedings.026

\begin{abstract}
The study was intended to explore the use of digital media and demand for EMI (English as Medium of Instruction) contents in higher education engineering sector. EMI is being increasingly implemented via top-down policies, sometimes with little attention to the educational implications that learning through a second language can have for the millions of students affected. Thus, this research aims to fill this void in its exploration of the effects of EMI on language learning, content learning, teaching delivery, quality of education, inequalities of access, language flexibility and hybridity, the competencies needed to be a successful EMI teacher, and other multi-faceted aspects of EMI. The research provides the results of the study connected with the investigation of implementing EMI within the Master of Engineering program in Peter the Great Saint-Petersburg Polytechnic University. The results obtained are compared with the ones presented by the EMI Oxford research group having conducted a profound study on the analysis of expanding implementation of EMI on a world scale. The article serves the interest for those who research digital trends in education as well as those who are interested in introducing EMI into the educational process.
\end{abstract}

Keywords: English as Medium of Instruction (EMI); Master program; Engineering; Foreign language; Digitized contents; ICT (information and communication technology) university curriculum.

\section{Introduction}

Currently, in all countries of the world, including Russia, there is an increasing trend of using English as a means of teaching academic subjects. This approach to the use of English is called EMI (English as Medium of Instruction) - "the use of English for teaching academic subjects in countries or jurisdictions where English is not the first language (L1) for the majority of the population". 
Despite the urgency of this problem, it is necessary to state the almost complete lack of serious research on this topic in Russia. In 2014, representatives of Oxford EMI, with the assistance of the British Council, conducted the first largescale study aimed at confirming the growing popularity of the use of English for teaching academic subjects in nonEnglish-speaking countries of the world, as well as identifying the main problems that arise with this approach to teaching [11]. The results of the study were presented in the report by Julie Dearden [19]. The problem of teaching academic subjects in English attracts the attention of researchers, developers of relevant programs and directly teachers who implement this approach.

The purpose of this article is to present the results of a study aimed at identifying a number of features of the EMI approach implementation in training Master of Engineering students and to compare these results with global trends in EMI training. To solve the problems of the study, the literature review and the analysis of the program documents related to the experience of implementing the EMI approach in different countries and identifying problems associated with this process was carried out.

The problem of using English as a means of teaching academic subjects (EMI) has been widely covered in scientific publications of researchers around the world [1], [2], [4], [6], [7], [8], [10], [12], [23], [24]. At the University of Oxford, a special center for research and development has been established to study the problem of EMI (Oxford EMI: Center for Research and Development on English Medium Instruction) [11]. It was the representatives of this center, together with members of the British Council, who conducted a world-wide study from October 2013 to March 2014 (representatives of 55 countries took part in the study), which aimed to get a detailed picture of the scale of the use of English as a teaching tool, as well as to identify the features of this process in different countries. The findings were presented in the report "English as a medium of instruction: a growing global phenomenon" by Julie Dearden [19]. It is worth noting that this report does not contain data on Russia. The report includes a description of the methodology of the study (two stages: primary and main); the main conclusions concerning the confirmation of the growing popularity of the implementation of this approach in the educational process; the review of the policies of individual states in connection with the adoption or rejection of this approach; the prospects for the implementation of EMI in different countries; the public point of view on this process; problems arising in the process of teaching and learning within EMI; the problem of internationalization of higher education; as well as a call for the academic community to continue research in the field of EMI implementation. The report itself is a 34-page text with graphic information, as well as tables; in addition, photocopies of the EMI seminars are attached to the text of the report. From our point of view, due to the scale of the project and the absolute significance of both quantitative and qualitative information, this particular document is of the greatest interest to researchers of the EMI implementation problem. The opportunities offered by the digital education are relevant to the goals of reforming modern education systems. Thanks to these technologies new forms of education have emerged - distant and blended, the unified information and education space of universities are being created.

This paper presents only some of the conclusions of the report that are directly relevant to our research. In particular, the report notes that some survey participants believe that, from a social point of view, the implementation of EMI is controversial, since teaching in English may limit access to education for students from low-income socio-economic groups and/or because of concerns that this may negatively affect the use of their native language and national identification. It is also noted that the educational infrastructure in many countries does not guarantee high-quality education within the framework of EMI: there is a shortage of teachers with good linguistic training; there is no established level of English proficiency required for training under EMI; there is an insufficient number of organizational and pedagogical guidelines of a recommendatory nature that contribute to effective teaching based on EMI. Educational programs of teachers' professional development practically do not address the problems of training within the framework of EMI. One of the issues raised in the report is the issue of knowledge control. What is being evaluated: the English language or the content of the subject? (What is being assessed: English or the subject content?). Should an EMI teacher take on the responsibility of teaching not only the subject, but also the English language? The report notes that the teachers who took part in the preliminary survey were all opposed to being required to teach in English. In the future, many noted that in the implementation of knowledge control, they evaluated only the content side and ignored the way of presenting this material, that is, the language design [19], [20]. Another problem highlighted in the report is the establishment of a certain level of language proficiency for both students and teachers in the digitized education. Digitized education has peculiar characteristics of learning tools that should be considered as their natural qualities that can be used with didactic purposes. General didactic properties of such form of education are based on their two key functions - informative and communicative - and are used in any educational system. These properties are manifested at all stages of the learning process - from the presentation of educational information to its consolidation and control.

The main didactic property of digitized education is multimedia. Multimedia gives mobile and computer devices some signs of animation: it is possible to show videos, full-color images, speak and understand individual phrases, listen to music, play animation, etc. All this, in its turn, contributes to the increase of learning motivation, speed of learning and development of skills. Multimedia allows the formation of skills that are impossible to form with the help of other technologies, for example, pronunciation in the study of a foreign language. Research by psychologists in this field shows that the enrichment of sensory experience formed in the process of perception of reality is a necessary condition for the mental development of a person. 
The initial level of human mental and intellectual development is the sensory-perceptual level. Modern multimedia can provide the creation of a special system for the development of sensory-perceptual abilities of a person, make it possible to demonstrate those processes and phenomena that a person cannot directly perceive due to the limitations of the senses. In multimedia learning systems, along with training and error analysis, there is mainly the following type of learning: visually presented communicative situation - inclusion in it - achievement of some result. The use of such technologies in the process of teaching foreign languages leads to some changes in the structure of learning activities. Spatial parameters of subject-subject interaction, communicative components of activity, its needs-motivational regulation, goal-setting, etc. are transformed. In the process of applying multimedia programs and resources, a number of important methodological problems are solved which sometimes cannot be solved in traditional (without the use of digital technology) instruction:

- adaptation to the authentic language environment;

- formation of a vivid visual image of the country and society of the language being studied;

- simulation of the linguistic and structural environment.

Thus, the use of multimedia programs and resources in foreign language teaching has a number of undoubted advantages, which consist in the multidimensional presentation of educational information and create a more natural atmosphere for language learning, as students can simultaneously see, hear and speak, in the ability to combine all four types of speech activity in one task. The report states that respondents from different countries mention a different desired level for students: from "good enough" to B2 (CEF) level. With regard to teachers, it is noted that not all highly qualified teachers of special subjects speak English at a sufficient level to conduct classes within the framework of EMI, while younger teachers who have a better command of the language do not have sufficient professional knowledge and experience in teaching specific professional subjects. On the other hand, when implementing the EMI approach, priority may be given to foreigners, native speakers, as a result of which local teachers, highly qualified specialists, may lose their jobs. Another problematic issue is who will contribute to helping students master English if teachers in the EMI approach do not consider it their responsibility. At the same time, EMI teachers generally believe that students generally improve their English proficiency in their classes, at least in reading and understanding professional texts in English, and it is the students themselves who should be responsible for the progress in mastering English.

Among the approaches to solving the problems mentioned above, it is possible to distinguish the suggestion of der Walt and Kidd to use both English and local languages in some educational situations, for example, to create instructions for tests [23]. We must admit that the length of this article does not allow us to cover in detail all the problems discussed in the Oxford EMI report, as well as other researchers of EMI implementation; At the same time, it is worth noting that all of the provisions related to EMI listed in the report are also considered by other researchers to some extent, and the Julie Dearden report is the most comprehensive, revealing the essence of the EMI phenomenon, which is why this part of the article was based mainly on the provisions of this report.

Many universities, both foreign and domestic, for example, Peter the Great St. Petersburg Polytechnic University (SPbPU), with the goal of integrating into the world space and attracting foreign students, include courses in their training programs that involve teaching academic subjects in English. For example, according to data from foreign researchers, there were more than 64,000 EMI programs in Europe in 2013 [13], [17], [18], [20], [23]. SPbPU currently has more than 200 courses taught in English [14]. The multidimensional nature and significance of the findings contained in this report prompted us to conduct our own research and analyze the features of implementing the EMI approach [3], [5], [7], [9], [15], [22]. The university offers a wide range of Master Degree Programs in English in various areas of expertise.

To prove the title of a true 'cosmopolitan university' SPbPU has launched a wide range of international educational programs and cutting-edge projects, expanded international and English-speaking faculty, increased enormously a number of out-bound and inbound talented students [14]. It allows students to acquire international experience in a pertinent area of expertise, broaden scientific horizons and streamline their skills [15], [16], [21], [22]. The university offers a wide range of Master of Engineering Degree Programs in English in the following areas:

1. Civil Engineering;

2. Energy Efficient and Sustainable Building;

3. Environmental Engineering in Urban Construction;

4. Emergency Preparedness and Response;

5. Energy Technology;

6. Power Plant Engineering;

7. Electrical Engineering;

8. Nuclear Power Engineering;

9. New Materials and Additive Technologies;

10. Laser and Fiber Optic Systems;

11. Microelectronics of Telecommunication Systems;

12. Continuum Mechanics: Fundamentals and Applications;

13. Mechanics and Mathematical modeling;

14. Intelligent Systems. 
All the students (both foreign and native speakers) gain practical skills in up-to-date and state-of-the-art labs at the university and perform academic and research activity using a plenty of helpful resources. With the aim to deliver pertinent knowledge and develop practical skills in the most efficient way the following teaching methods are applied:

- implementation of problem-based teaching methods;

- organization of research projects;

- development of students' motivation;

- simulation of learning activity (i.e., creation of a virtual linguistic space);

- organization of self-evaluation and group evaluation.

Game applications and computer games, programs for 3D communication with the help of avatars - Second Life, Machinima - are used both in distance and mixed forms of foreign language teaching. Quite often elements of gamification are used in open educational resources, in tests. For example, the web-based test creation platform Quizlet https://quizlet.com has recently launched two templates to create interactive tests of Gravity and Scatter format, based on maximum visualization of educational material. Software developers offer very easy-to-use game builders or game engines that language teachers can use to design their own game scenarios and game assignment formats.

Scientific research activities and publishing. These activities imply working in re-search labs as well as writing scientific articles under a professor's supervision. Students might get their research and scientific articles published on global citation web-sites. Students gain practical skills in the highly equipped and modern laboratories of the university and carry out research activities using many resources of SPbPU. Studying in English in the Master program is a step that guarantees future master students significant achievements in the professional field and the beginning of a successful career.

\section{Methods}

Theoretical foundations for the study are the methodological principles of teaching a foreign language in the format of mixed and online learning (by means of ICT), principles of professionally-oriented teaching of a foreign language, as well as the basic principles of the communicative approach to teaching a foreign approach to foreign language teaching. The material of the study served as theoretical works devoted to creation and evaluation of courses in the format of blended and online learning. As the main methods of research were questionnaire survey, analysis of scientific literature.

\section{Experiment}

With the advent of digitized education, which provides vast amounts of knowledge and information at any time and place, the need for special competencies in education and learning has arisen. Today, no one questions the fact that it is not just possible, but necessary to introduce digital technologies into the pedagogical process but, unfortunately, often the use of innovative methods based on such technologies do not facilitate and optimize learning activities, but rather overloads and complicates them, leading to frustrations and failures.

In collaboration with the Graduate School of Engineering Pedagogy, Psychology and Applied Linguistics, the main research method was chosen to conduct interviews with the creators of the course "History and Methodology of Science" (taught in English), Civil Engineering Institute for the relevant areas of training. The course was developed with the use of e-learning technologies and placed in the electronic information and educational environment on the basis of SPbPU MOOK platform. Foreign Languages Department This course is mandatory for all the first year Master students. The course examines the historical and methodological aspects of Engineering as a field of science. Its task is to demonstrate that despite the historical variability, there are certain criteria of scientific character, in particular, the requirement to implement a certain scientific methodology, which, with all the rigor and objectivity of scientific knowledge, cannot do without the subjectivity of the researcher. The course is taught in the frames of integration of digital technology in the educational process. An anonymous survey of students who completed this course was also conducted, and a number of personal interviews with students were organized.

The study was conducted at Peter the Great St. Petersburg Polytechnic University in the frames of Master of Engineering programs (Civil Engineering Institute). The students under review were only non-native English speakers. What distinguished this course from similar courses taught at SPbPU was the fact that this course was taught to the 1styear postgraduate students without their preliminary taking the course of English for Specific Purposes (ESP). The absence of the ESP course in the Master program curriculum was explained by the peculiarities of the English language training program in 2017-2019, which involved teaching English only within the framework of the Foreign language in professional communication course. Thus, the course "History and methodology of science" was actually the introduction to the majoring field of studies, equal to the similar course in Russian. 


\section{Results}

The survey was attended by 5 course developers, 20 lecturers (10 institutes) who give lectures and practical classes, and 119 students having attended this course. The response score range is from 0 to 10 , where 0 is the lowest score. The most important information provided by the course developers when analyzing their experience of teaching the previously mentioned course is presented in Table 1, Figure 1:

\begin{tabular}{lll}
\hline Main difficulties & Evaluated aspects & Result in \% \\
\hline Language proficiency level & Lack of general knowledge of & 30 \\
& English & \\
& Lack of professional & 47 \\
& vocabulary & 23 \\
Self-motivation evaluation & High level & 44 \\
& Average level & 33 \\
& Low level & 16 \\
Students' analytical skills & High level & 22 \\
& Average level & 62 \\
\multirow{5}{*}{ Students' self-responsibility } & Low level & 45 \\
& High level & 31 \\
\multirow{5}{*}{ Knowledge control } & Average level & 24 \\
\multirow{3}{*}{ Academic writing skills } & Low level & 10 \\
& Language proficiency level & 90 \\
& Course content & 29 \\
& High level & 32 \\
& Average level & 49
\end{tabular}

Table 1. Results of Course developers' opinion poll

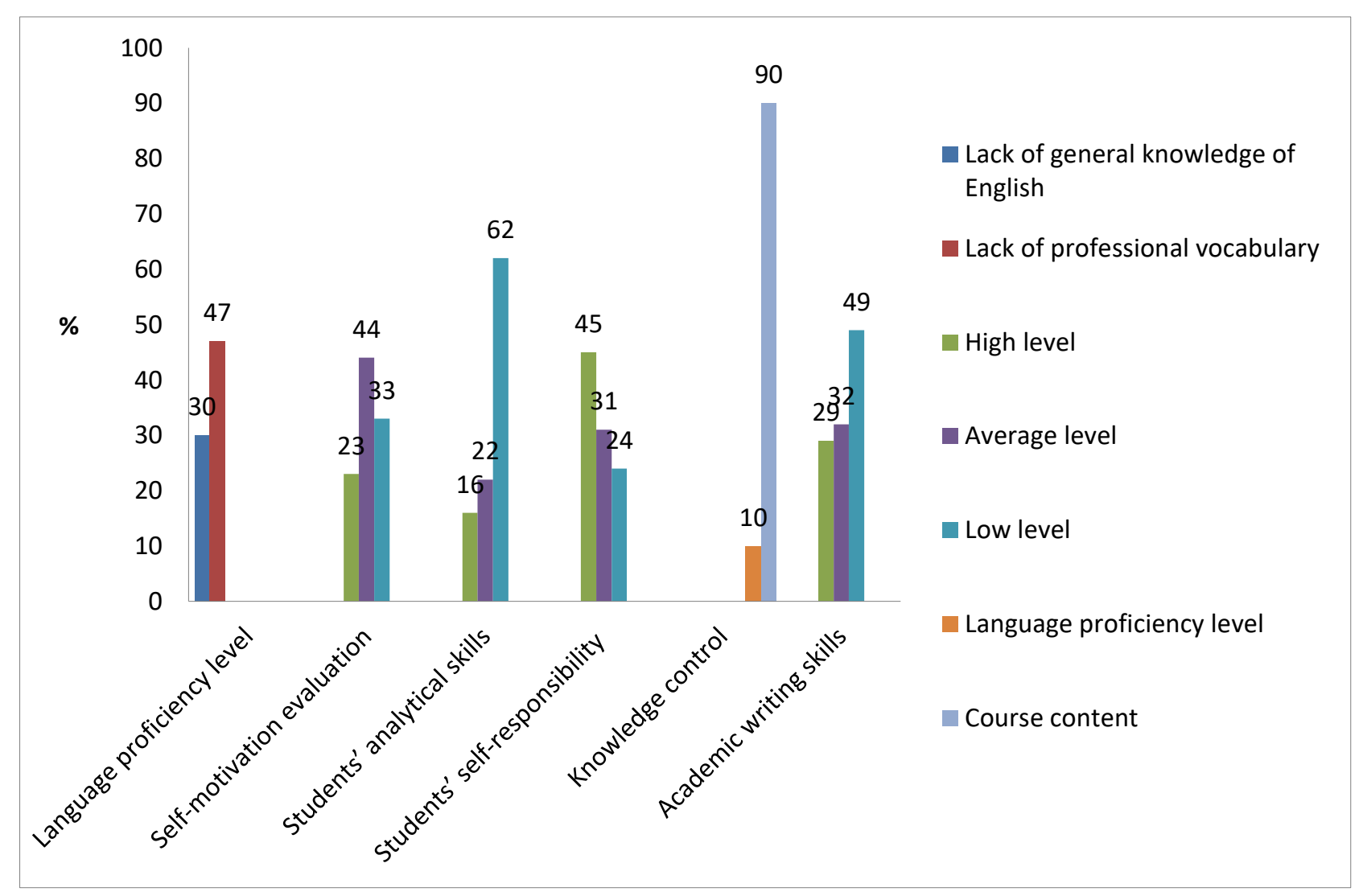

Fig. 1. The analysis of the experience of teaching the course 
While teaching, the lecturers had to adjust the course to the level of the English language proficiency of the students, since the students had a rather low level of proficiency in general vocabulary, which made it difficult to master the main course material, including the introduction of professional vocabulary. One third of students do not have the knowledge of academic vocabulary.

Mastering the course was complicated by the lack of serious academic work skills, as well as general skills related to the analysis and the ability to correctly formulate the thoughts in a foreign language. When performing control tasks, some of the students' works were almost plagiarism, which was explained both by the inability to work independently with volumes of information and the lack of academic skills in general, and by the difficulty of expressing their ideas in English. Both the irresponsibility of students and the desire to facilitate work by cheating were noted, which, according to the authors of the article, sharply distinguished Russian students from foreign ones.

As the lecturers noted, the control of knowledge was carried out without taking into account the level of the English language proficiency, the emphasis was on checking the content of the material offered for assimilation (the lecturers do not consider themselves obliged, in addition to teaching special students, to teach English as well).

Despite the complexity of the course, as noted by the students, some students did an excellent job with the course tasks. The success was due not so much to the level of the English language proficiency required for the course, but to the responsibility when working in the classroom and completing assignments.

During the interview, the course developers first stressed that the main thing for students to master the course in English was to have a sufficiently high level of General English proficiency, and it was possible to learn professional vocabulary during the course. However, in the future, the lecturers expressed a wish related to the fact that before passing the course, it was desirable for students to master the professional academic vocabulary. There were also suggestions for strengthening the requirements for the initial level of the students' English language proficiency when entering programs taught in a foreign language, up to the introduction of the internal exam in English. At the moment, the English language exam is being included in the tests required for the admission to these areas of training.

After completing the course, students were given an anonymous questionnaire. Of the 124 students who formally took this course, 119 students took part in the survey. For most students, this course was the first course taught in English, with knowledge of the subject being assessed in English. The results of the student's survey are presented in Table 2, Figure 2:

\begin{tabular}{lll}
\hline Main difficulties & Evaluated aspects & Result in \% \\
\hline Language proficiency level & Lack of general knowledge of & 25 \\
& English & \\
& Lack of professional & 45 \\
& vocabulary & 10 \\
Self-motivation evaluation & High level & 70 \\
& Average level & 20 \\
& Low level & 25 \\
Students' analytical skills & High level & 34 \\
& Average level & 41 \\
& Low level & 3 \\
Students' self-responsibility & High level & 6 \\
& Average level & 91 \\
& Low level & 10 \\
Knowledge control & Language proficiency level & 90 \\
& Course content & 29 \\
Academic writing skills & High level & 32 \\
& Average level & 49
\end{tabular}

Table 2. Results of Master students' opinion poll

Approximately two-thirds of the students who answered the questionnaire noted that they had difficulties with both general and professional English vocabulary. The majority also noted the difficulties associated with preparing an abstract in English (mainly, ignorance of the structural features of writing such academic works in English). Assessing their motivation in mastering the course, most noted an average level. Among the explanations for the low motivation, the students noted the previously mentioned difficulties, as well as the lack of awareness of the importance of studying majors in English, as well as problems associated with "too voluminous materials offered for assimilation" and "the monotony of the classes' design" (from the comments of students). When asked whether the course improved the level of the foreign language proficiency, the overwhelming majority (85\%) answered positively. 


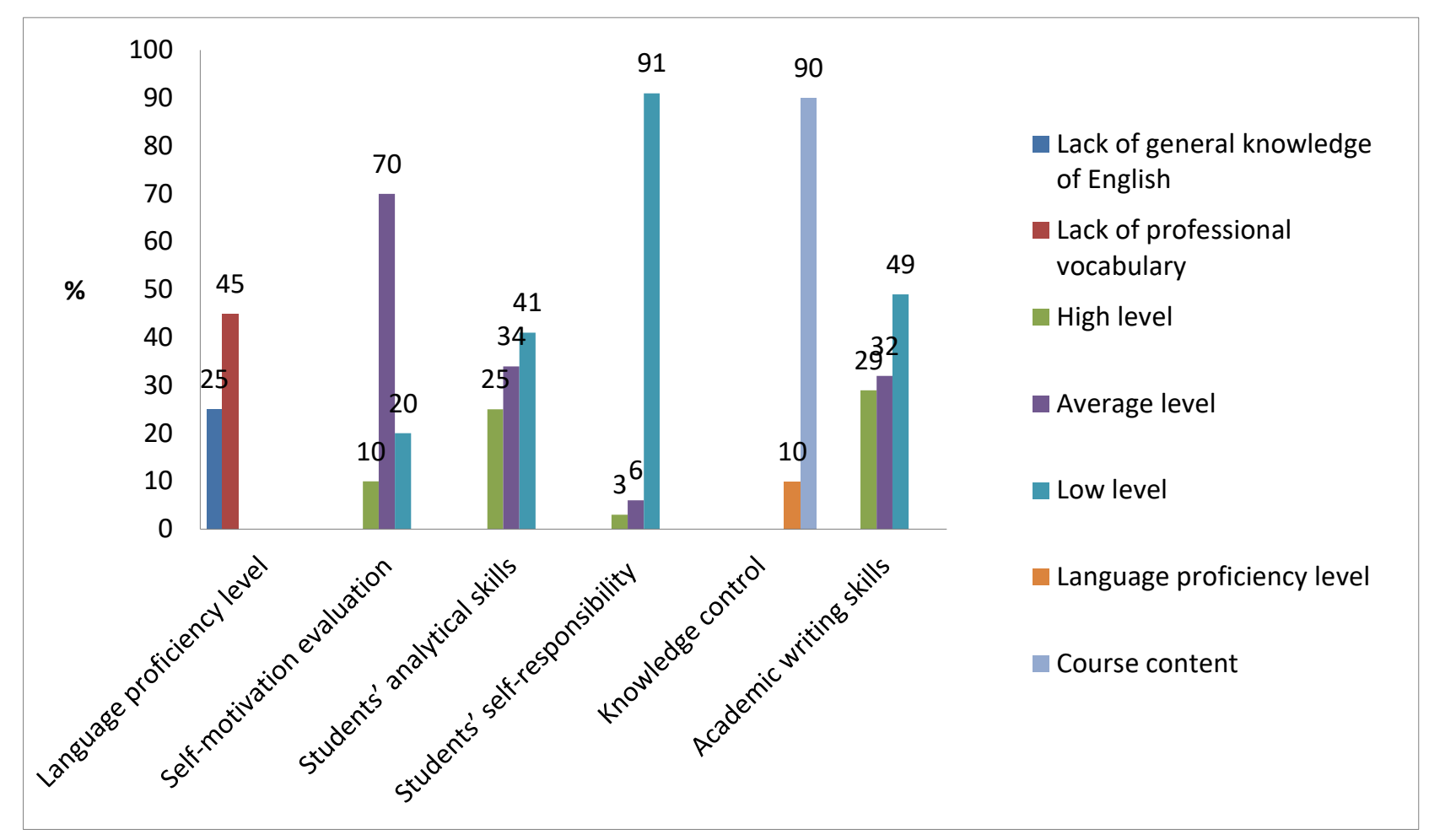

Fig. 2. The analysis of the results of the student's survey

The majority of respondents $(96 \%)$ supported the possibility of parallel teaching of their majors in English by the lecturers in majors and conducting ESP classes aimed at familiarizing with the specific vocabulary and features of the professional communication in English in oral and written forms. 25\% noted the opportunity to do without an introductory course in their majoring field of study and to give lectures and conduct seminars in English at once. In general, all students noted the need to include professionally-oriented courses in English in the university curriculum. At the same time, $80 \%$ considered that these courses should be included in the mandatory program, and $20 \%$ - as an elective.

As a result of the personal interviews with students, the interviewers identified a dual attitude of students to passing a professionally-oriented course in English in their first year. On the one hand, there was a clear interest of students in this course and awareness of the seriousness of the approach to teaching the majors, on the other hand there were doubts about the validity of the introduction of this course when students have not mastered the basics of their major.

The analysis of the results obtained in the study on the implementation of the EMI approach in the frames of Master of Engineering programs allowed stating that the main problems identified in the study are similar to the problems raised in the Oxford EMI report.

The main common problems are the lack of requirements for the level of the English language proficiency on the part of students and the conduct of knowledge control, in which the knowledge of professional realities was subjected to control, while the language design was absolutely not evaluated, without which it is impossible to talk about the formation of the foreign-language professional competence.

The positive aspects of the introduction of the course "History and methodology of science" are the high professional level of the lecturers chosen for the development and implementation of this course. The fact of the introduction of this course within the first year of the Master program without having mastered the basics of the academic and professional vocabulary in English can be considered a drawback. However, it should be noted that this drawback was taken into account and subsequently a solution was found to overcome it.

The only significant drawback noted by the authors is the fact that the high-quality education provided by SPbPU to those who do not speak English is not available. Even if the L2 of the students before admission was a foreign language other than English, it is English that becomes a mandatory language for mastering. A lot of majors are taught in English and are not duplicated in Russian. A low level of the English language proficiency or the lack of knowledge of it is a serious obstacle for the students to enter the University and to be further trained. These facts indicate the existence of social problems associated with social inequality, and may cause discontent among some segments of the population.

\section{Conclusion}

In conclusion, it should be noted that the conducted research may be of interest to those who are engaged in the study of new trends in education, as well as those who directly consider the problem of implementing EMI into the educational process both in higher educational institutions, and in secondary educational schools and vocational educational institutions. 
The advantage of the courses conducted in the English language is a large selection of materials, as the number of professional academic texts, textbooks and anthologies in English is much greater than in similar publications in Russian. The main obstacles to achieving the objectives of the course lie far beyond the language itself. To optimize the use of innovation technologies methodologically sound and expedient application of them should take into account and be based on the basic conditions for their successful integration into the educational process, namely:

1) provision of technical equipment of a university or school and computer security of the learning process;

2) formation of information and learning environment of higher education institution or school, which is a unified system of software, databases, electronic teaching and methodological resources and other elements that implement information and educational processes;

3) sustainable motivation of a teacher and a student;

4) the level of development of information and communication competence of teachers and students.

In general, the problem of implementing EMI-based e-learning in Russia is quite undeveloped and therefore presents great prospects for further research.

\section{References}

[1] Alenkina, T. (2020). English medium instruction in the Russian university. Vysshee Obrazovanie v Rossii, Vol. 29, No. 1, pp. 98-103., DOI:10.31992/0869-3617-2020-29-1-98-103

[2] Almazova, N., Barinova, D., Ipatov, O. (2018). Forming of information culture with tools of electronic didactic materials. In: Annals of DAAAM and Proceedings of the International DAAAM Symposium, Vol. 29, No.1, pp. 0587-059., DOI:10.2507/29th.daaam.proceedings.085

[3] Almazova, N., Krylova, E., Rubtsova, A., Odinokaya, M. (2020). Challenges and opportunities for Russian higher education amid covid-19: Teachers' perspective. Education Sciences, Vol. 10, No.12, pp. 1-11

[4] Anderson, K. D. (2004): The Nature of Teacher Leadership in Schools as Reciprocal Influences Between Teacher Leaders and Principals. School Effectiveness and School Improvement, No. 15, pp. 97-113., DOI:10.1076/sesi.15.1.97.27489

[5] Bekirogullari, Z., Bylieva, D., Lobatyuk, V., Nam, T. (2021). How Virtual Personal Assistants Influence Children's Communication. Lecture Notes in Networks and Systems, No. 184, pp. 112-124., DOI:10.1007/978-3-030-65857$1 \_12$

[6] Botha, W. (2013): English-medium instruction at a university in Macau: Policy and realities. World Englishes, No. 32, pp. 461-475., DOI:10.1111/weng.12053

[7] Bylieva, D., Lobatyuk, V., Fedyukovsky, A. (2019). Ways of sociotechnical integration of scientists and volunteers in citizen science. IOP Conference Series Materials Science and Engineering, DOI:10.1088/1757899X/940/1/012150

[8] Chappel, J. (2015). Teaching in English Is Not Necessarily the Teaching of English. International Education Studies, Vo. 8, No. 3, DOI:10.5539/ies.v8n3p1

[9] Chernysheva, M.A., Kozlova, A.O., Donova, E.V. (2019). Obuchenie akademicheskogo pis'ma na angliiskom yazyke russkoyazychnykh nauchno-pedagogicheskikh rabotnikov (iz opyta raboty). Vysshee obrazovanie v Rossii, Vol. 28, No .10, pp. 50-57., DOI:10.31992/0869-3617-2019-28-10-50-57

[10] Doiz, A., Lasagabaster D., Sierra, J.M. (Eds.). (2013). English-medium instruction at universities: Global challenges. Clevedon: Multilingual Matter, DOI:10.1093/elt/cct045

[11] http://www.education.ox.ac.uk/crdemi-oxford, (2021). EMI Oxford: Centre for Research and Development on English Medium Instruction, Accessed on: 2021-03-21.

[12] Hasan, Al-W. (2016). Role of Using English as medium of Instruction in Reshaping Bahraini Senior Teachers' Perceptions of Their Roles as Middle Leadership in their Schools. Journal of Language and Education No. 1, pp. 615., DOI:10.17323/2411-7390-2016-2-1-6-15

[13] Hollenbeck, A., Kalchman, M. (2012). Professional development for conceptual change: Extending the paradigm to teaching reading comprehension in US schools. Professional Development in Education, Vol. 39, No. 5, pp. 638655., DOI:10.1080/19415257.2012.728535

[14] https://www.spbstu.ru/international-cooperation/international-educational-programs/international-graduateprograms/graduate-programs-in-english, (2021). International Master's Degree Programs, Accessed on: 2021-03-21

[15] Karpovich, I., Odinokaya, M. (2020). Interactive technology of pedagogical assistance as a means of adaptation of foreign first-year students. IOP Conference Series Materials Science and Engineering, DOI:940. 10.1088/1757899X/940/1/012130

[16] Klochkova E., Volgina A., Dementyev S., Klochkov $\quad$ Y. $\quad$ (2016). Human FactorinQualityFunctionDeployment.SecondInternationalSymposiumon Stochastic Models in Reliability Engineering, Life Science and Operations Management (SMRLO), IEEE, 466-468, DOI:10.1109/SMRLO.2016.81

[17] Lukacs, K.S., Galluzzo, G.R. (2014). Beyond empty vessels and bridges: Toward defining teachers as the agents of school change. Teacher Development: An international journal of teachers' professional development, Vol. 18, No. 1, pp. 100-106., DOI:10.1080/13664530.2013.856338 
[18] Lo, Y.Y. (2017). Development of the beliefs and language awareness of content subject teachers in CLIL: Does professional development help? International Journal of Bilingual Education and Bilingualism. Advance online publication, DOI:10.1080/13670050.2017.1318821.

[19] Macaro, E., Curle, S., Pun, J., An, J., Dearden, J. (2018). A systematic review of English medium instruction in higher education. Language Teaching, Vol. 51, No. 1, pp. 36-76., https:// https://dx.doi.org/10.1017/S0261444817000350

[20] O'Dowd, R. (2018). The training and accreditation of teachers for English medium instruction: an overview of practice in European universities. International Journal of Bilingual Education and Bilingualism Vol.21, No. 5, pp. 553-563., Doi:10.1080/13670050.2018.1491945

[21] Rubtsova, A., Odinokaya, M., Krylova, E., Smolskaia, N. (2021). Problems of Mastering and Using Digital Learning Technology in the Context of a Pandemic. Lecture Notes in Networks and Systems, No. 184, pp. 324-337.

[22] Shipunova, O., Berezovskaya, I., Smolskaia, N. (2019). The Role of Student's Self-actualization in Adapting to the e-Learning Environment. TEEM'19: Proceedings of the Seventh International Conference on Technological Ecosystems for Enhancing Multiculturality, DOI:745-750. 10.1145/3362789.3362884.

[23] Wiseman, A., Odell, A. (2021). Should non-English-speaking countries teach in English? Available from: https://www.britishcouncil.org/voices-magazine/should-nonenglish-speaking-countries-teach-in-english, Accessed: 2021-03-21. 